\title{
Intrathecal hyperbaric $2 \%$ prilocaine versus $0.4 \%$ plain ropivacaine for same-day arthroscopic knee surgery: a prospective randomized double-blind controlled study
}

\section{Prilocaïne $2 \%$ hyperbare versus ropivacaïne $0,4 \%$ en injection intrathécale pour une arthroscopie du genou en chirurgie ambulatoire: une étude randomisée contrôlée prospective à double insu}

\author{
José Aguirre, MD · Alain Borgeat, MD · Philipp Bühler, MD · Jelena Mrdjen, MD • \\ Beat Hardmeier, MD $\cdot$ John M. Bonvini, MD \\ Received: 15 December 2014 / Revised: 2 June 2015 / Accepted: 16 July 2015 / Published online: 14 August 2015 \\ (C) Canadian Anesthesiologists' Society 2015
}

\begin{abstract}
Background Short-duration spinal anesthesia is a good option for ambulatory knee surgery. Hyperbaric $2 \%$ prilocaine has short onset and rapid recovery times and, therefore, may be well suited in this setting. The aim of this study was to compare the times to reach motor block, motor block resolution, and discharge from the postanesthesia care unit (PACU) between hyperbaric $2 \%$ prilocaine and $0.4 \%$ plain ropivacaine.
\end{abstract}

This article is accompanied by an editorial. Please see Can J Anesth 2015; 62: this issue.

Author contributions José Aguirre, Alain Borgeat, and Beat Hardmeier contributed substantially to the conception and design of the study. José Aguirre, Philipp Bühler, John M. Bonvini, and Beat Hardmeier contributed substantially to the analysis and interpretation of data. José Aguirre and John M. Bonvini drafted the article. José Aguirre, Alain Borgeat, and John M. Bonvini revised the article for important intellectual content. Philipp Bühler revised the article critically. Jelena Mrdjen substantially contributed to the acquisition of data and helped draft the article.

J. Aguirre, MD · A. Borgeat, MD (ه)

Division of Anesthesiology, Balgrist University Hospital Zurich, Forchstrasse 340, 8008 Zurich, Switzerland

e-mail: alain.borgeat@balgrist.ch

P. Bühler, MD · J. M. Bonvini, MD

Institute of Anesthesiology, University Hospital Zurich, Zurich, Switzerland

J. Mrdjen, MD · B. Hardmeier, MD

Hospital Lachen, Institute of Anesthesiology, Lachen,

Switzerland
Methods In this prospective randomized double-blind study, 140 patients (ages 18-80 yr and American Society of Anesthesiologists physical status I-II) scheduled for elective unilateral arthroscopic knee surgery lasting $<45$ min were allocated to either $3 \mathrm{~mL}$ of $2 \%$ prilocaine $(60 \mathrm{mg})$ or $3 \mathrm{~mL}$ of $0.4 \%$ plain ropivacaine $(12 \mathrm{mg})$. Time to reach complete recovery of motor block, time to reach criteria for discharge, as well as side effects up to $48 \mathrm{hr}$ after discharge were recorded.

Results The median (interquartile range [IQR]) time to recovery from the motor block was faster in the $2 \%$ prilocaine group compared with the $0.4 \%$ ropivacaine group (180 [169240] $\min$ vs 240 [180-300] min, respectively; median difference, $60 \mathrm{~min}$, 95\% confidence interval (CI), 23 to 97 min; $P=0.036)$. The median [IQR] time to reach discharge criteria was similar between the two groups (330 [295-365] min vs, 335 [290-395] min; median difference 5 min, 95\% CI, -25 to $35 \mathrm{~min} ; P=0.330$ ). The incidence of side effects was low and similar in both groups. No case of transient neurologic symptoms occurred in either group.

Conclusion The recovery of motor block was faster after intrathecal administration of hyperbaric $2 \%$ prilocaine compared with $0.4 \%$ plain ropivacaine; however, discharge time was similar between the two groups. Both drugs showed a similar risk profile.

\section{Résumé}

Contexte La rachianesthésie de courte durée est une bonne option lorsqu'on pratique une chirurgie ambulatoire du genou. Le délai d'action de la prilocaïne $2 \%$ hyperbare est court et son temps de récupération rapide; cet agent 
pourrait donc être adapté pour cette indication. L'objectif de cette étude était de comparer le temps jusqu'à installation du bloc moteur, jusqu'à résolution du bloc moteur, et jusqu'au congé de la salle de réveil entre la prilocaïne $2 \%$ hyperbare et la ropivacaïne 0,4\%.

Méthode Dans cette étude randomisée prospective à double insu, 140 patients (âgés de 18 à 80 ans et de statut physique I-II selon l'American Society of Anesthesiologists) devant subir une arthroscopie unilatérale du genou non-urgente d'une durée de moins de 45 minutes ont reçu soit $3 \mathrm{~mL}$ de prilocä̈ne $2 \%(60$ $\mathrm{mg}$ ), ou $3 \mathrm{~mL}$ de ropivacaïne 0,4\% (12 $\mathrm{mg})$. Le temps jusqu'à résolution complète du bloc moteur, le temps jusqu'à atteinte des critères nécessaires au congé, ainsi que les effets secondaires jusqu'à $48 \mathrm{~h}$ après le congé ont été enregistrés.

Résultats Le temps médian (écart interquartile [ÉIQ]) jusqu'à récupération du bloc moteur était plus court dans le groupe prilocaïne $2 \%$ que dans le groupe ropivacaïne 0,4 \% (180 [169-240] min vs. 240 [180-300] min, respectivement; différence médiane, $60 \mathrm{~min}$, intervalle de confiance (IC) $95 \%, 23$ à $97 \mathrm{~min} ; P=0,036$ ). Le temps médian [ÉIQ] jusqu'à atteinte des critères de congé était semblable dans les deux groupes (330 [295-365] min vs. 335 [290-395] min; différence médiane 5 min, IC $95 \%$, -25 à 35 min; $P=0,330$ ). L'incidence d'effets secondaires était faible et semblable dans les deux groupes. Il n'y a pas eu de cas de symptôme neurologique transitoire.

Conclusion La récupération après un bloc moteur est plus courte après l'administration intrathécale de prilocaïne $2 \%$ hyperbare comparativement à la ropivacaïne 0,4\%; toutefois, le temps jusqu'au congé était semblable dans les deux groupes. Le profil de risque des deux médicaments était semblable.

Same-day surgery has gained popularity and success due to proper patient selection and associated positive outcomes. ${ }^{1-3}$ Moreover, fast-track anesthetic techniques for day surgery that facilitate earlier hospital discharge ${ }^{4,5}$ have been introduced to reduce in-hospital associated costs. ${ }^{6}$

Spinal anesthesia has been a focus of attention in sameday surgery. ${ }^{7-9}$ Both short- and long-acting local anesthetics have been used and were shown to have advantages and disadvantages. ${ }^{10-12}$ The ideal spinal anesthetic for same-day surgery should provide rapid and adequate anesthesia for an appropriate duration, followed by rapid regression of sensory and motor blockade, rapid bladder voiding, and minimal residual effects to facilitate early ambulation. ${ }^{13-15}$

Prilocaine is characterized by rapid onset and regression of sensory and motor blockade and a good safety profile, ${ }^{16-20}$ while ropivacaine is a long-lasting local anesthetic. $^{21,22}$ Ratsch et al. showed faster block recovery, which translated into faster discharge, ${ }^{10}$ with the use of hyperbaric $2 \%$ prilocaine $60 \mathrm{mg} v s$ hyperbaric $0.5 \%$ bupivacaine $15 \mathrm{mg}$ for ambulatory spinal anesthesia.

To date, studies are lacking that compare intrathecal use of hyperbaric $2 \%$ prilocaine with $0.4 \%$ plain ropivacaine, which the latter is known to have faster recovery times than bupivacaine. $^{23,24}$ The primary outcome of this study was the time from spinal anesthesia to complete motor block resolution. Secondary outcomes were time to discharge from the postoperative care unit (PACU), onset time of spinal block, time to first spontaneous bladder voiding, and the incidence of side effects (bradycardia, hypotension) and complications, including transient neurological symptoms (TNS).

\section{Methods}

After obtaining approval from the local ethics committee (Ethikkommission Kt. Luzern, Nr: 831) and written informed consent from participants, 140 American Society of Anesthesiologists I-II patients scheduled for elective unilateral arthroscopic knee surgery lasting $<45$ min were enrolled in this prospective double-blind singlecentre controlled trial. Group allocation was performed according to a computerized randomization list. Exclusion criteria were age $<18 \mathrm{yr}$, age $>80 \mathrm{yr}$, obesity (body mass index $>40 \mathrm{~kg} \cdot \mathrm{m}^{-2}$ ), known or suspected coagulopathy (international normalized ratio $>1.2$ ), thrombocytopenia (platelet count $<100,000 \bullet \mu \mathrm{L}^{-1}$ ), known peripheral neuropathy or neurological deficits, chronic pain disorders, history of postoperative nausea and vomiting (PONV), pregnancy, and known allergy to study drugs.

The anesthetic solutions $(3 \mathrm{~mL}$ of commercially available hyperbaric $2 \%$ prilocaine $[60 \mathrm{mg}$ ] or $3 \mathrm{~mL}$ of specially prepared $0.4 \%$ plain ropivacaine $[12 \mathrm{mg}]$ ) were handed to the anesthesiologist in a blinded fashion (in a pre-prepared syringe) immediately before puncture. Premedication was performed $30 \mathrm{~min}$ prior to anesthesia induction with oral paracetamol $1 \mathrm{~g}$ and oral midazolam $7.5 \mathrm{mg}$. Standard monitoring with continuous 3-lead electrocardiogram, noninvasive blood pressure, and pulse oximetry was initiated in the induction room, and an intravenous peripheral access was obtained. Ringer's lactate solution was infused at a rate of $4 \mathrm{~mL} \cdot \mathrm{kg}^{-1} \cdot \mathrm{hr}^{-1}$ throughout the procedure. Patients were placed in the lateral recumbent position on the surgical side, and the L3/ L4 intervertebral space was then manually identified and marked. After disinfection and draping of the puncture site, local anesthesia was performed with a subcutaneous injection of $2 \mathrm{~mL}$ of $1 \%$ lidocaine. Spinal anesthesia was 
performed via the paramedian approach using a $27 \mathrm{G}$ pencil point needle, and the anesthetic solution was injected over a period of $30 \mathrm{sec}$ with the bevel pointing upward. Patients were then immediately turned to the supine position, and dermatome extension of sensory blockade was assessed every five minutes with cold spray stimulation in the anterior axillary line. Motor blockade was also assessed every five minutes after injection according to the Bromage score which ranges from 1 to 4 (where $1=$ no motor block; $2=$ partial block, able to flex the knee and ankle; $3=$ partial block, only plantar flexion of the ankle possible; $4=$ complete block, no voluntary movement of the limb possible). Successful anesthesia was defined as a target dermatome of T10 and a Bromage score of 4 achieved at 20 min following the injection.

Bradycardia $<45$ beats $\cdot \min ^{-1}$ was treated with atropine $0.01 \mathrm{mg} \cdot \mathrm{kg}^{-1} i v$. Hypotension, defined as systolic blood pressure $<85 \mathrm{mmHg}$, was treated with (1) ephedrine 5-10 mg $i v$, (2) a second dose of ephedrine, and (3) additional fluid replacement with intravenous administration of 250 $\mathrm{mL}$ of hydroxyethyl starch $\left(\right.$ Voluven $\left.^{\circledR}\right)$ if required. Oxygen was applied via nasal cannula if $\mathrm{SpO}_{2}$ decreased to $<95 \%$.

According to our clinical standard and for patient comfort, mild to moderate sedation was performed with propofol using a target-controlled infusion with effect-site concentrations of 0.5 to a maximum of $0.8 \mu \mathrm{g} \cdot \mathrm{mL}^{-1}$. Sedation was monitored using the modified Observer's Assessment of Alertness/Sedation Scale (where a score of $4=$ lethargic responses to name in normal tone, corresponding to mild sedation levels; and a score of $3=$ responds only after name is called loudly and/or repeatedly, corresponding to moderate sedation levels). Rescue analgesia was achieved using fentanyl up to $0.1 \mathrm{mg} i v$ if necessary.

The patients were transferred to the PACU following surgery where a study nurse unaware of the study group assignment registered the following parameters: time of motor block regression to Bromage score 1; time of sensory block regression to dermatome T12 using temperature discrimination; pain using the visual analogue scale (VAS), where $0=$ no pain to $100=$ worst pain imaginable; time of first spontaneous bladder voiding; first oral liquid intake; the incidence of nausea (patient's subjective sensation of feeling sick or wishing to vomit); vomiting (expulsion of gastric content); headache; discomfort or pain at the puncture site; and the occurrence of TNS, defined as burning pain and dysesthesia in the L5/S1 dermatomes. In our setting, the PACU is linked to the day hospital; patients are discharged to home from this location, avoiding physical transfer to the ward. According to our protocol, the standard criteria for home discharge were VAS $<30$, bilateral regression of sensory block below T12 level, Aldrete score $\geq 8,{ }^{25}$ no surgical bleeding, and no PONV. In addition, spontaneous bladder voiding, regression of motor block (Bromage score 1), uncomplicated oral liquid intake, and no neurologic deficits were required.

Postoperative analgesia was accomplished with oral paracetamol $1 \mathrm{~g}$ at six hourly intervals and oral etodolac $300 \mathrm{mg}$ at 12 hourly intervals. Additionally, a bolus of morphine $0.05 \mathrm{mg} \cdot \mathrm{kg}^{-1}$ iv was given for severe pain (VAS > 60) during the PACU stay.

Prior to patient discharge home, overall patient satisfaction (range from $1=$ absolutely satisfied to $10=$ absolutely not satisfied) was recorded.

On the second postoperative day after surgery, a study nurse unaware of study group assignment interviewed all patients by telephone regarding side effects (urinary retention, headache, pain at the puncture site), with special focus on neurologic complications, especially TNS (according to the criteria described by Hampl et al. ${ }^{26}$ and Zaric et al..$^{27}$

\section{Statistics}

According to an unpublished pilot study, interindividual standard deviation of time to motor block recovery from $0.4 \%$ ropivacaine was $60 \mathrm{~min}$. A reduction of $30 \mathrm{~min}$ using $2 \%$ prilocaine was considered clinically significant. Therefore, using type I $(\alpha)$ and type II $(\beta)$ errors of 0.05 and 0.2 , respectively, we calculated that a sample size of 64 patients in each group would be necessary. To compensate for possible drop outs, we enrolled 70 patients per group.

Non-normally distributed continuous variables were analyzed using the Mann-Whitney U test with Bonferroni correction, with differences between groups described as the difference in medians. For non-normally distributed variables, $95 \%$ confidence intervals (CIs) of the differences in the medians between groups were constructed using the bootstrap procedure with 10,000 replications. Normally distributed continuous variables were analyzed using the Student's $t$ test and described using differences in means with conventionally constructed $95 \%$ CIs. Chi square ${ }^{2}$ tests were used to analyze categorical variables. All reported $P$ values are two sided. Statistical analysis was performed using SPSS ${ }^{\circledR}$ version 22 (IBM, NY, USA) and Numbers '09 version 2.1 (Apple Inc., Cupertino, CA, USA) software.

\section{Results}

One hundred forty patients were included in the study during January 2011to December 2012. Seventy patients were randomized to each group. In the prilocaine group, five patients did not complete the study. There was one 
Figure Study design according to the CONSORT statement

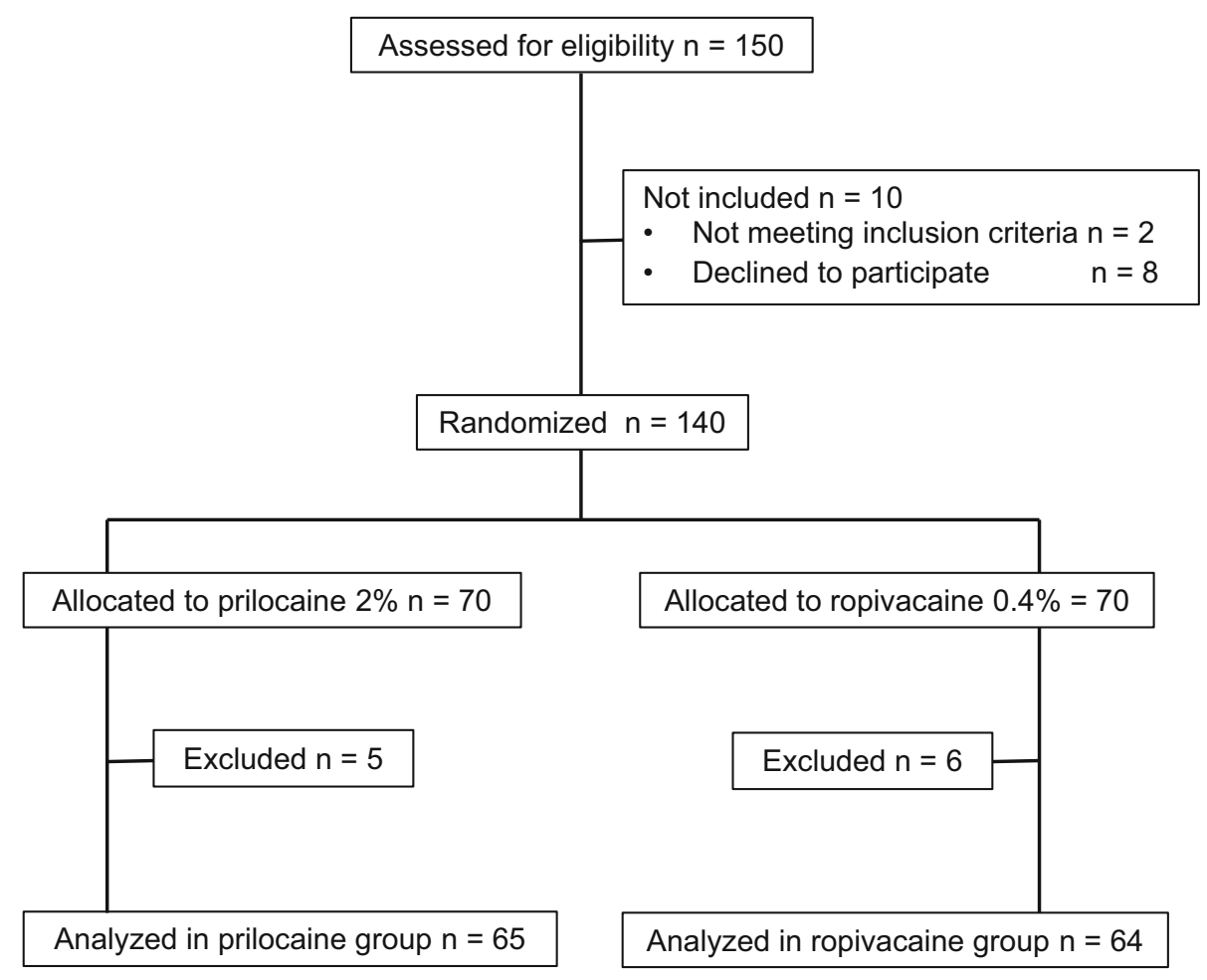

Flow diagram according to CONSORT statement. technical failure of spinal anesthesia (difficulty in reaching the subdural space due to bone deformities) requiring general anesthesia, three protocol violations (surgery time $>80 \mathrm{~min}$ ) with need for general anesthesia, and one case of hemodynamic instability (after application of intravenous antibiotics) requiring treatment (Figure). In the ropivacaine group, six patients did not complete the study. There were two failures of spinal anesthesia (difficulty in reaching the subdural space due to bone deformities) requiring general anesthesia, three protocol violations (surgery time $>80 \mathrm{~min}$ ) with need for general anesthesia, and one withdrawal of consent prior to spinal anesthesia (Figure). Side effects of two patients in the prilocaine group could not be collected (Table 4).

Patient demographics were similar in both groups (Table 1).

The mean (SD) time to onset of sensory block was significantly shorter in the $2 \%$ prilocaine group than in the $0.4 \%$ ropivacaine group [4.2 (1.1) min vs 5.2 (1.0) min, respectively; $P<0.001]$. The required block level (T10 within $20 \mathrm{~min}$ ), intensity of sensory and motor block, and motor block onset time were similar between the two groups (Table 2). Maximum sensory block level was similar between groups (T5 for prilocaine vs T6 for ropivacaine). All patients tolerated the tourniquet during
Table 1 Demographic data

\begin{tabular}{lll}
\hline Patient characteristics & $\begin{array}{l}\text { Prilocaine } 2 \% \\
(n=65)\end{array}$ & $\begin{array}{l}\text { Ropivacaine 0.4\% } \\
(n=64)\end{array}$ \\
\hline Male/female $(n)$ & $40 / 25$ & $41 / 23$ \\
Age $(\mathrm{yr})$ & $48(18)$ & $51(24)$ \\
Weight $(\mathrm{kg})$ & $71(15)$ & $74(18)$ \\
Height $(\mathrm{cm})$ & $170(8)$ & $172(6)$ \\
ASA class I/II $(n)$ & $35 / 30$ & $40 / 24$
\end{tabular}

Data expressed as number or mean (SD). ASA = American Society of Anesthesiologists classification

the whole procedure without administration of rescue analgesia or increase in sedation. Surgical times were comparable between groups.

Patients in the $2 \%$ prilocaine group had a significantly faster median (interquartile range [IQR]) resolution of motor block than patients in the $0.4 \%$ ropivacaine group (180 [169-240] min vs 240 [180-300] min, respectively; median difference, $60 \mathrm{~min}, 95 \%$ confidence interval (CI), 23 to $97 \mathrm{~min} ; P=0.036$ ), while there was no difference in sensory block regression between groups (120 [120-180] min vs 120 [70-180] min, respectively; median difference, $0 \mathrm{~min}$; $95 \% \mathrm{CI},-29$ to $29 \mathrm{~min} ; P=0.702$ ) (Table 2). The median [IQR] time to spontaneous bladder voiding was also similar between groups (250 [231-300] min vs 270 
Table 2 Block characteristics

\begin{tabular}{|c|c|c|c|c|}
\hline Block characteristics & $\begin{array}{l}\text { Prilocaine } 2 \% \\
(n=65)\end{array}$ & $\begin{array}{l}\text { Ropivacaine } 0.4 \% \\
(n=64)\end{array}$ & $\begin{array}{l}\text { Difference between groups } \\
\text { ( } 95 \% \text { CI of difference) }\end{array}$ & $P$ value \\
\hline Maximal sensory block & T5 [T4-T7] & T6 [T5-T8] & - & - \\
\hline Time sensory block onset (T10) (min) & $4.2(1.0)$ & $5.2(1.1)$ & $1(0.6$ to 1.3$)$ & $<0.001$ \\
\hline Sensory block offset (T12) (min) & $120[120-180]$ & $120[70-180]$ & $0(-29$ to 29$) \dagger$ & 0.702 \\
\hline Maximal motor block 20 min: Bromage 1-2-3-4 $(n)$ & $0-0-0-65$ & $0-0-0-64$ & - & - \\
\hline Time offset motor block (Bromage 1) (min) & 180 [169-240] & 240 [180-300] & $60(23$ to 97$) \dagger$ & 0.036 \\
\hline
\end{tabular}

Data are expressed as number, mean (SD), or median [interquartile range]. The difference between groups is for the ropivacaine group compared with the prilocaine group

$\dagger$ Bootstrapped $95 \%$ confidence interval with 10,000 replications. $P$ value from Mann-Whitney U test; CI $=$ confidence interval

Table 3 Block times

\begin{tabular}{|c|c|c|c|c|}
\hline Time & $\begin{array}{l}\text { Prilocaine } 2 \% \\
(n=65)\end{array}$ & $\begin{array}{l}\text { Ropivacaine } 0.4 \% \\
(n=64)\end{array}$ & $\begin{array}{l}\text { Difference between groups } \\
\text { (95\% CI of the difference) } \dagger\end{array}$ & $P$ value \\
\hline Surgery time (min) & 21 [20-44] & 25 [21-35] & $4(-0.1$ to 8.1$)$ & 0.100 \\
\hline $\begin{array}{l}\text { Time from SPA until end of surgery } \\
\text { (min) }\end{array}$ & 55 [46-61] & 56 [50-68] & $1(-2$ to 4$)$ & 0.059 \\
\hline Time to first oral intake (min) & 130 [120-169] & 125 [100-180] & $-5(-24$ to 14$)$ & 0.489 \\
\hline $\begin{array}{l}\text { Time to first spontaneous voiding } \\
\text { (min) }\end{array}$ & $250[231-300]$ & $270[235-320]$ & $20(-9$ to 49$)$ & 0.185 \\
\hline $\begin{array}{l}\text { Time from SPA to discharge home } \\
\text { (min) }\end{array}$ & 330 [295-365] & 335 [290-395] & $5(-25$ to 35$)$ & 0.330 \\
\hline
\end{tabular}

Data are expressed as median [interquartile range]. The difference between groups is for the ropivacaine group compared with the prilocaine group

$\dagger$ Bootstrapped $95 \%$ confidence interval with 10,000 replications. $P$ value from Mann-Whitney $\mathrm{U}$ test. CI $=$ confidence interval; SPA $=$ spinal anesthesia

Table 4 Block side effects

\begin{tabular}{llll}
\hline Time & $\begin{array}{l}\text { Prilocaine } 2 \% \\
(n=63)\end{array}$ & $\begin{array}{l}\text { Ropivacaine } 0.4 \% \\
(n=64)\end{array}$ \\
\hline Pain at discharge (NRS 0-10) & $0[0-1]$ & $0[0-0]$ & 0.082 \\
Nausea & $1(1.6 \%)$ & $3(4.7 \%)$ & 0.317 \\
Vomiting & $0(0 \%)$ & $1(1.6 \%)$ & 0.319 \\
Hypotension (SBP $<85 \mathrm{mmHg})$ & $14(22 \%)$ & $19(29.7 \%)$ & 0.338 \\
Bradycardia (HR $<45$ beats.min $\left.{ }^{-1}\right)$ & $3(4.8 \%)$ & $0(0 \%)$ & 0.479 \\
Headache & $0(0 \%)$ & $0(0 \%)$ & 1 \\
Backache & $0(0 \%)$ & $0(0 \%)$ & 1 \\
Transient neurological symptoms & $0(0 \%)$ & & 1 \\
\hline
\end{tabular}

Data are expressed as number $(\%)$ or median [interquartile range]

$\mathrm{HR}=$ heart rate; $\mathrm{NRS}=$ numeric rating scale; $\mathrm{SBP}=$ systolic blood pressure

[235-320] min, respectively; median difference, $20 \mathrm{~min}$; $95 \% \mathrm{CI},-9$ to $49 \mathrm{~min} ; P=0.185$ ) (Table 3 ). There was no need for urinary catheter insertion in either group.

The median [IQR] time from spinal anesthesia to discharge home was similar in both groups (330 [295-
365] $\mathrm{min}$ vs, 335 [290-395] min; median difference $5 \mathrm{~min}$, 95\% CI, -25 to $35 \mathrm{~min} ; P=0.330$ ) (Table 3 ).

Pain at discharge, analgesic consumption, and the occurrence of side effects were similar between groups (Table 4). All patients but one (satisfaction score 8) were 
completely satisfied with the procedure and the investigation without differences between groups.

Follow-up at $48 \mathrm{hr}$ did not detect any complications in either group. In particular, no transient neurological symptoms were reported in either group (Table 4).

\section{Discussion}

This study showed that intrathecal hyperbaric $2 \%$ prilocaine has a significantly faster onset of sensory block and a significantly faster recovery from motor block compared with $0.4 \%$ plain ropivacaine; however, the faster recovery of motor block in the $2 \%$ prilocaine group did not translate into faster discharge times.

Previous studies reported that varying the concentration of local anesthetic may affect the potency of spinal anesthesia. $^{28,29}$ The decision to reduce the concentration of the commercially available $0.5 \%$ ropivacaine was based on the clinical experience that this concentration leads to a longer lasting motor block. Moreover, studies have shown that concentrations of $0.5 \%$ and $0.4 \%$ had similar efficacy and relative potency after intrathecal application for lower limb surgery. ${ }^{30}$ The choice of a $12 \mathrm{mg}$ dose for the $0.4 \%$ ropivacaine group was in accordance with results of different dose-finding studies. ${ }^{22,31,32}$ For prilocaine, the dose of $60 \mathrm{mg}$ was chosen in accordance with the results of a study by Camponovo et al. Their study results showed that $13 \%$ of patients receiving $40 \mathrm{mg}$ of intrathecal hyperbaric $2 \%$ prilocaine and none of the patients receiving $60 \mathrm{mg}$ of plain prilocaine needed supplementary analgesics prior to the end of surgery. ${ }^{33}$

The discharge time of patients in the plain ropivacaine group was in accordance with other studies comparing plain ropivacaine with hyperbaric ropivacaine at doses up to $15 \mathrm{mg}^{34-37}$ Nevertheless, it is difficult to compare sensory or motor recovery due to a number of differences between the various studies, including study design, injection techniques (median, paramedian, slow injection, needle orifice facing up or toward the patient's head/toe), ${ }^{11,33}$ needles $(25-27 \mathrm{G}),{ }^{33,38}$ location of lumbar space (L1/L2 - L4/L5), ${ }^{38,39}$ patient management after injection (immediate turning to supine position or remaining in the lateral position for a longer period), ${ }^{38-40}$ and motor scales (Bromage, modified Bromage scale). ${ }^{33,35,41,42}$

The mean (SD) time from spinal anesthesia to discharge home was 346 (73) $\mathrm{min}$ in the ropivacaine group. This time is in accordance with the mean (SD) values found by Casati et al. [322 (57) $\mathrm{min}$ ] in patients scheduled for inguinal herniorrhaphy under unilateral spinal anesthesia. ${ }^{38}$ Cappelleri et al. had a shorter discharge time (197 min; range, $177-218 \mathrm{~min})$ using a smaller dose $(7.5 \mathrm{mg}$ ) for knee arthroscopy ${ }^{40}$; however, they used hyperbaric ropivacaine and kept the patients in the lateral decubitus position for 15 min after injection. Breebaart et al. had a comparable mean (SD) discharge time [305 (73) min] despite using a larger dose $(15 \mathrm{mg})$ of plain ropivacaine but at a higher concentration $(0.75 \%){ }^{43}$

The $2 \%$ prilocaine group showed a mean (SD) discharge time of 334 (55) min, which is comparable with previous data from Hampl et al. ${ }^{26}$ (253 min after $50 \mathrm{mg}$ hyperbaric $2 \%$ prilocaine) and Ratsch et al. ${ }^{10}$ (308 min after hyperbaric $2 \%$ prilocaine $60 \mathrm{mg}$ ). As previously mentioned, the differences in time can be explained by different techniques used for spinal anesthesia, dosages, and discharge criteria.

Urinary retention has been reported in $25 \%$ of patients after $60 \mathrm{mg}$ of intrathecal prilocaine. ${ }^{44}$ In our study, this side effect was not observed in either group. Nevertheless, in the present work, the mandatory bladder voiding requirement before discharge could have prolonged the discharge time. In this study, the mean (SD) bladder voiding time in the ropivacaine group was achieved after 273 (61) min, which is consistent with other studies. ${ }^{38,40,43}$

Sensory onset time was significantly faster in the $2 \%$ prilocaine group, but the spread of the sensory block was comparable in both groups. In contrast, Ratsch et al. found a significantly higher sensory block spread with hyperbaric $0.5 \%$ bupivacaine compared with hyperbaric $2 \%$ prilocaine, but the patients were in the sitting position after injection. ${ }^{10}$

The mean (SD) sensory (T12 level) and motor block regression (Bromage 1) in the ropivacaine group were 137 (78) $\mathrm{min}$ and 225 (81) min, respectively. These times are longer when compared with other studies but can be explained by different patient positioning, ${ }^{38}$ lower drug dosage, ${ }^{40}$ and ropivacaine concentration. ${ }^{43}$

The incidence of side effects was low and similar in both groups. Back pain did not occur in either group. This was a concern for intrathecal ropivacaine, since early reports showed a $28 \%$ incidence of back pain. ${ }^{45}$ Nevertheless, these findings were not confirmed by other studies. $^{44}$

No transient neurological symptoms occurred in either group, which is in accordance with current literature, ${ }^{27,33,39,46}$ suggesting that both local anesthetics are safe for same-day spinal anesthesia. The low mean (SD)VAS at discharge [9 (2) for prilocaine; 5 (1) for ropivacaine] associated with high patient satisfaction and uneventful follow-up showed that both hyperbaric $2 \%$ prilocaine and $0.4 \%$ plain ropivacaine were equally safe for short-lasting same-day spinal anesthesia.

In conclusion, recovery from motor block was significantly faster in the hyperbaric $2 \%$ prilocaine group, but this potential advantage did not translate into a faster 
time to discharge to home. This finding can likely be explained by the strict discharge criteria used in this investigation. This issue warrants further investigation through testing of different drug dosages and discharge criteria. Side effects and patient satisfaction were similar in the two groups. Both hyperbaric $2 \%$ prilocaine and plain $0.4 \%$ ropivacaine are reasonable choices for same-day arthroscopic knee surgery.

\section{Disclosure of funding None.}

Conflicts of interest No commercial or non-commercial affiliations are, or may be perceived to be, a conflict of interest with the work of each author, and there are no other associations, such as consultancies.

\section{References}

1. Troy AM, Cunningham AJ. Ambulatory surgery: an overview. Curr Opin Anaesthesiol 2002; 15: 647-57.

2. Lermitte $J$, Chung F. Patient selection in ambulatory surgery. Curr Opin Anaesthesiol 2005; 18: 598-602.

3. Shnaider I, Chung F. Outcomes in day surgery. Curr Opin Anaesthesiol 2006; 19: 622-9.

4. Mulroy MF, Larkin KL, Hodgson PS, Helman JD, Pollock JE, Liu SS. A comparison of spinal, epidural, and general anesthesia for outpatient knee arthroscopy. Anesth Analg 2000; 91: 860-4.

5. Mulroy $M F$, Salinas $F V$, Larkin KL, Polissar NL. Ambulatory surgery patients may be discharged before voiding after shortacting spinal and epidural anesthesia. Anesthesiology 2002; 97: 315-9.

6. Williams BA, Kentor ML. Fast-track ambulatory anesthesia: impact on nursing workload when analgesia and antiemetic prophylaxis are near-optimal. Can J Anesth 2007; 54: 243-4.

7. Bartusseck E, Fatehi S, Motsch J, Grau T. Survey on practice of regional anaesthesia in Germany, Austria, and Switzerland. Part 1: Quality assurance and training concepts (German). Anaesthesist 2004; 53: 836-46.

8. Rawal N. Analgesia for day-case surgery. Br J Anaesth 2001; 87: 73-87.

9. Urmey WF. Spinal anaesthesia for outpatient surgery. Best Pract Res Clin Anaesthesiol 2003; 17: 335-46.

10. Ratsch G, Niebergall H, Hauenstein L, Reber A. Spinal anaesthesia in day-case surgery. Optimisation of procedures (German). Anaesthesist 2007; 56: 322-7.

11. Kallio H, Snall EV, Tuomas CA, Rosenberg PH. Comparison of hyperbaric and plain ropivacaine $15 \mathrm{mg}$ in spinal anaesthesia for lower limb surgery. Br J Anaesth 2004; 93: 664-9.

12. Milligan $K R$. Recent advances in local anaesthetics for spinal anaesthesia. Eur J Anaesthesiol 2004; 21: 837-47.

13. Liu SS, McDonald SB. Current issues in spinal anesthesia. Anesthesiology 2001; 94: 888-906.

14. Kopp SL, Horlocker TT. Regional anaesthesia in day-stay and short-stay surgery. Anaesthesia 2010; 65(Suppl 1): 84-96.

15. Vagts DA, Bley $C H$, Mutz $C W$. Use of $2 \%$ hyperbaric prilocaine for spinal anesthesia: sensitivity analysis in outpatient surgery (German). Anaesthesist 2013; 62: 271-7.

16. de Weert $K$, Traksel M, Gielen M, Slappendel R, Weber E, Dirksen $R$. The incidence of transient neurological symptoms after spinal anaesthesia with lidocaine compared to prilocaine. Anaesthesia 2000; 55: 1020-4.
17. Ostgaard $G$, Hallaraker $O$, Ulveseth $O K$, Flaatten $H$. A randomised study of lidocaine and prilocaine for spinal anaesthesia. Acta Anaesthesiol Scand 2000; 44: 436-40.

18. Kishimoto $T$, Bollen $A W$, Drasner $K$. Comparative spinal neurotoxicity of prilocaine and lidocaine. Anesthesiology 2002; 97: $1250-3$

19. Ruetsch YA, Boni T, Borgeat A. From cocaine to ropivacaine: the history of local anesthetic drugs. Curr Top Med Chem 2001; 1: $175-82$.

20. Takenami T, Yagishita S, Nara Y, Hoka S. Intrathecal mepivacaine and prilocaine are less neurotoxic than lidocaine in a rat intrathecal model. Reg Anesth Pain Med 2004; 29: 44653.

21. Wille $M$. Intrathecal use of ropivacaine: a review. Acta Anaesthesiol Belg 2004; 55: 251-9.

22. van Kleef $J W$, Veering BT, Burm AG. Spinal anesthesia with ropivacaine: a double-blind study on the efficacy and safety of $0.5 \%$ and $0.75 \%$ solutions in patients undergoing minor lower limb surgery. Anesth Analg 1994; 78: 1125-30.

23. Mantouvalou $M$, Ralli $S$, Arnaoutoglou $H$, Tziris $G$, Papadopoulos G. Spinal anesthesia: comparison of plain ropivacaine, bupivacaine and levobupivacaine for lower abdominal surgery. Acta Anaesthesiol Belg 2008; 59: 65-71.

24. Kallio H, Snall EV, Kero MP, Rosenberg PH. A comparison of intrathecal plain solutions containing ropivacaine 20 or $15 \mathrm{mg}$ versus bupivacaine $10 \mathrm{mg}$. Anesth Analg 2004; 99: 713-7.

25. Aldrete JA. The post-anesthesia recovery score revisited. J Clin Anesth 1995; 7: 89-91.

26. Hampl KF, Heinzmann-Wiedmer S, Luginbuehl I, et al. Transient neurologic symptoms after spinal anesthesia: a lower incidence with prilocaine and bupivacaine than with lidocaine. Anesthesiology 1998; 88: 629-33.

27. Zaric D, Pace NL. Transient neurologic symptoms (TNS) following spinal anaesthesia with lidocaine versus other local anaesthetics. Cochrane Database Syst Rev 2009: CD003006.

28. Camorcia $M$, Capogna $G$, Berritta $C$, Columb $M O$. The relative potencies for motor block after intrathecal ropivacaine, levobupivacaine, and bupivacaine. Anesth Analg 2007; 104: 904-7.

29. Camorcia M, Capogna $G$, Columb MO. Minimum local analgesic doses of ropivacaine, levobupivacaine, and bupivacaine for intrathecal labor analgesia. Anesthesiology 2005; 102: 646-50.

30. Xu T, Wang $J, L i S$. The relative potency ration of intrathecal $0.5 \%$ and $0.4 \%$ ropivacaine for lower limb surgery. Eur $\mathrm{J}$ Anaesthesiol 2011; 28: 123 (abstract).

31. Wahedi $W$, Nolte $H$, Klein P. Ropivacaine for spinal anesthesia. A dose-finding study (German). Anaesthesist 1996; 45: 737-44.

32. McNamee DA, Parks L, McClelland AM, et al. Intrathecal ropivacaine for total hip arthroplasty: double-blind comparative study with isobaric $7.5 \mathrm{mg} \mathrm{ml}(-1)$ and $10 \mathrm{mg} \mathrm{ml}(-1)$ solutions. $\mathrm{Br}$ J Anaesth 2001; 87: 743-7.

33. Camponovo C, Fanelli A, Ghisi D, Cristina D, Fanelli G. A prospective, double-blinded, randomized, clinical trial comparing the efficacy of $40 \mathrm{mg}$ and $60 \mathrm{mg}$ hyperbaric $2 \%$ prilocaine versus $60 \mathrm{mg}$ plain $2 \%$ prilocaine for intrathecal anesthesia in ambulatory surgery. Anesth Analg 2010; 111: 568-72.

34. Gautier PE, De Kock M, Van Steenberge A, et al. Intrathecal ropivacaine for ambulatory surgery. Anesthesiology 1999; 91: 1239-45.

35. Khaw KS, Ngan Kee WD, Wong $M, N g F$, Lee A. Spinal ropivacaine for cesarean delivery: a comparison of hyperbaric and plain solutions. Anesth Analg 2002; 94: 680-5.

36. Chung CJ, Choi SR, Yeo KH, Park HS, Lee SI, Chin YJ. Hyperbaric spinal ropivacaine for cesarean delivery: a comparison to hyperbaric bupivacaine. Anesth Analg 2001; 93: $157-61$. 
37. Fettes PD, Hocking G, Peterson MK, Luck JF, Wildsmith JA. Comparison of plain and hyperbaric solutions of ropivacaine for spinal anaesthesia. Br J Anaesth 2005; 94: 107-11.

38. Casati A, Moizo E, Marchetti C, Vinciguerra F. A prospective, randomized, double-blind comparison of unilateral spinal anesthesia with hyperbaric bupivacaine, ropivacaine, or levobupivacaine for inguinal herniorrhaphy. Anesth Analg 2004; 99: 1387-92.

39. Fanelli $G$, Danelli $G$, Zasa M, Baciarello M, Di Cianni S, Leone $S$. Intrathecal ropivacaine $5 \mathrm{mg} / \mathrm{ml}$ for outpatient knee arthroscopy: a comparison with lidocaine $10 \mathrm{mg} / \mathrm{ml}$. Acta Anaesthesiol Scand 2009; 53: 109-15.

40. Cappelleri $G$, Aldegheri $G$, Danelli $G$, et al. Spinal anesthesia with hyperbaric levobupivacaine and ropivacaine for outpatient knee arthroscopy: a prospective, randomized, double-blind study. Anesth Analg 2005; 101: 77-82.

41. Whiteside JB, Burke D, Wildsmith JA. Spinal anaesthesia with ropivacaine $5 \mathrm{mg} \mathrm{ml(-1)} \mathrm{in} \mathrm{glucose} 10 \mathrm{mg} \mathrm{ml(-1)} \mathrm{or} 50 \mathrm{mg} \mathrm{ml}$ (-1). Br J Anaesth 2001; 86: 241-4.
42. Bannister J, McClure JH, Wildsmith JA. Effect of glucose concentration on the intrathecal spread of $0.5 \%$ bupivacaine. $\mathrm{Br} \mathrm{J}$ Anaesth 1990; 64: 232-4.

43. Breebaart MB, Vercauteren MP, Hoffmann VL, Adriaensen HA. Urinary bladder scanning after day-case arthroscopy under spinal anaesthesia: comparison between lidocaine, ropivacaine, and levobupivacaine. Br J Anaesth 2003; 90: 309-13.

44. Kreutziger J, Frankenberger B, Luger TJ, Richard S, Zbinden S. Urinary retention after spinal anaesthesia with hyperbaric prilocaine $2 \%$ in an ambulatory setting. $\mathrm{Br} \mathrm{J}$ Anaesth 2010; 104: 582-6.

45. McDonald SB, Liu SS, Kopacz DJ, Stephenson CA. Hyperbaric spinal ropivacaine: a comparison to bupivacaine in volunteers. Anesthesiology 1999; 90: 971-7.

46. Hendriks MP, de Weert CJ, Snoeck MM, Hu HP, Pluim MA, Gielen MJ. Plain articaine or prilocaine for spinal anaesthesia in day-case knee arthroscopy: a double-blind randomized trial. Br J Anaesth 2009; 102: 259-63. 